\title{
Jordan tobacco dependence treatment guidelines: rationale and development
}

H. Ayub, ${ }^{1}$ N. Obeidat, ${ }^{1}$ S. Leischow, ${ }^{2}$ T. Glynn ${ }^{3,4}$ and F. Hawari, ${ }^{1,5}$

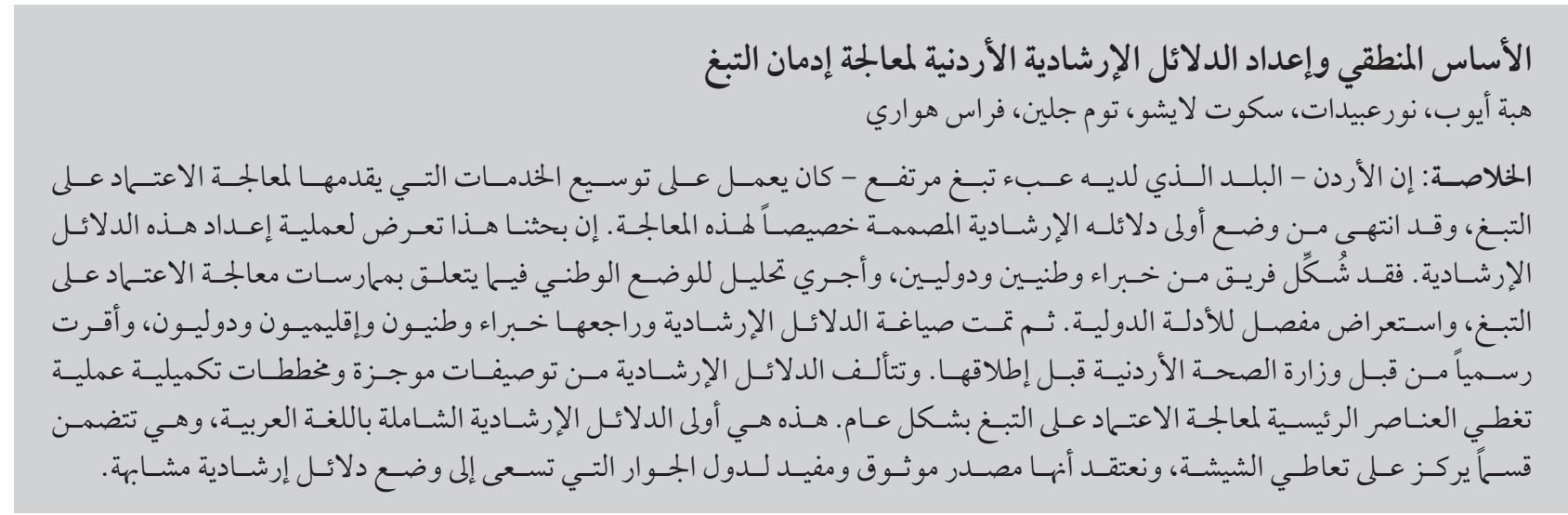

ABSTRACT Jordan, a high tobacco-burden country, has been working to expand its tobacco dependence treatment services and has completed development of its first customized treatment guidelines. Our paper presents the development process for these guidelines. A group of national and international experts was formed and a national situation analysis for tobacco dependence treatment practices and a detailed review of international evidence were conducted. The guidelines were then drafted and reviewed by national, regional and international experts and were official endorsed by the Jordanian Ministry of Health before being launched. The guidelines comprise concise descriptions and practical supplementary flowcharts covering the major elements of general tobacco dependence treatment. These are the first comprehensive Arabic-language guidelines, including a section focusing on waterpipe use, and we believe they are a reliable and useful resource for neighbouring countries seeking to develop similar guidelines.

Recommandations pour le traitement de la dépendance au tabac en Jordanie: argumentation et développement

RÉSUMÉ La Jordanie, un pays ayant une forte charge tabagique, a œuvré pour développer ses services de traitement de la dépendance au tabac et a terminé l'élaboration de ses premières recommandations thérapeutiques personnalisées. Notre article présente le processus de développement de ces recommandations. Un groupe d'experts nationaux et internationaux a été créé et une analyse de la situation nationale en matière de pratiques pour le traitement de la dépendance au tabac ainsi qu'un examen détaillé des preuves internationales ont été menés. Un projet de directives a ensuite été rédigé puis examiné par des experts nationaux, régionaux et internationaux et a été officiellement adopté par le ministère de la Santé jordanien avant son lancement. Les directives incluent des descriptions concises et des schémas pratiques supplémentaires couvrant les principaux éléments du traitement général de la dépendance au tabac. Il s'agit des premières recommandations exhaustives en langue arabe comprenant une partie axée sur l'utilisation de la pipe à eau, et nous pensons qu'elles représentent une ressource fiable et utile pour les pays voisins cherchant à élaborer des recommandations similaires. 


\section{Introduction}

Tobacco dependence treatment plays an essential role in tobacco control $(1,2)$. It is a health-care intervention that, if successfully integrated within health-care systems, will be of great value in managing the growing burden of noncommunicable diseases such as cardiovascular disease, cancer, diabetes and chronic respiratory disease, both globally and in the Arab world (3-5).

Jordan, a developing country in the Eastern Mediterranean Region, recently embarked on the process of developing national tobacco dependence treatment guidelines. This has become a pressing need because of the changing landscape of tobacco control issues in the country. Jordan has witnessed an alarming rise in the prevalence of tobacco use over recent years, increasing from $29 \%$ in 2007 to $32 \%$ in $2012(6,7)$. Furthermore, cardiovascular diseases and cancer are the leading causes of death, with rates of $35.9 \%$ and $14.6 \%$ respectively (8), which is not surprising in a population where $28 \%$ of adults suffer from chronic disease (9) and where $39 \%$ of cancer cases are tobacco-related (10).

Accordingly, greater efforts are being made to raise awareness about the management of smoking - an important modifiable risk factor common to Jordan's prevalent noncommunicable diseases - with the aim of emphasizing the chronic nature of tobacco dependence and the possibility of treatment (11). In line with such efforts, the Jordanian Ministry of Health $(\mathrm{MoH})$ and its partners have been working to expand tobacco dependence treatment services at clinics staffed by health-care professionals (HCPs) educated in tobacco dependence treatment. This is important because the availability of such services is currently limited to only a few clinics.
No officially endorsed national tobacco dependence treatment guidelines previously existed in Jordan. Developing such guidelines was thus seen by concerned parties as a useful step towards achieving multiple objectives:

- to compile all information related to tobacco dependence treatment that is relevant to Jordan in a single resource;

- to review the international research and guidelines on tobacco dependence treatment and create a comprehensive, standardized, evidence-based, yet locally-customized reference;

- to support ongoing educational efforts in the country;

- to reinforce the message that a systematic means of tobacco dependence treatment is required for implementation within health care settings;

- to provide an officially endorsed guideline to assist decision-makers responding to the call for integration of tobacco dependence treatment services into their systems; and

- to reaffirm the Jordanian MoH's commitment to the World Health Organization's Framework Convention on Tobacco Control (WHO FCTC) (12).

Creating standardized, evidencebased (13), locally relevant tobacco dependence treatment guidelines aims to facilitate the successful integration of tobacco dependence treatment into health-care systems. Article 14 of the WHO FCTC confirms the importance of having such guidelines, stating that abiding parties must "develop and disseminate appropriate, comprehensive and integrated guidelines based on scientific evidence and best practices, taking into account national circumstances and priorities" (14). Thus, while numerous evidencebased international guidelines exist which may be referred to (15-18), locally developed guidelines make it more likely that knowledge about tobacco dependence treatment is translated into practice by taking into account the characteristics of the audience and the environment within thatlocality (19), andbycommunicating scientific content in a manner that is more locally articulate and relevant than international guidelines would be. Furthermore, on the regional level, few Arab countries have developed their own Arabic language tobacco dependence treatment guidelines and none are available publicly. Jordan's guidelines will therefore be of use to other tobacco dependence treatment experts in the region who are seeking to expand treatment resources (20).

This paper aims to describe the process of developing a national tobacco dependence treatment guideline in Jordan. We hope that our paper can provide insights and communicate a learning experience to interested parties in the regional scientific community who are seeking to develop their own guidelines.

\section{Methods}

The guidelines were developed in collaboration with various stakeholders, and over several stages. King Hussein Cancer Centre (KHCC) and the Jordanian MoH were the 2 main parties spearheading the process. KHCC was founded in 1997 and is the only specialized tertiary comprehensive adult and paediatric cancer centre in Jordan. It is a nongovernmental institution which has offered its expertise to the improvement of cancer care throughout the region, and houses a Cancer Control Office which focuses on preventive aspects of cancer control in the country and the region. In developing the guidelines the Cancer Control Office worked closely with the Tobacco Control Department in the Jordanian $\mathrm{MoH}$, acting as the focal point for organizing and developing working 
groups and in ensuring progress over the stages of development.

Stage 1 (June 2013): Formation of the Jordan Tobacco Dependence Treatment Guidelines Group. The group comprised international tobacco dependence treatment experts recruited through Global Bridges-a collaborative international project with a network of tobacco dependence treatment professionals - and local experts from the Jordanian $\mathrm{MoH}$ and KHCC. A plan was set and approved by the group with regard to the stages through which the guidelines should be developed and reviewed.

Stage 2 (June-July 2013): Conduct ofanationalsituationanalysis. Anational situation analysis was conducted by $\mathrm{KHCC}$ and the Jordanian $\mathrm{MoH}$ to generate an overview of the situation in Jordan regarding current tobacco dependence treatment practices. The analysis was important for framing the existing gaps in, and hence the value of, systematic tobacco dependence treatment services, which in turn would benefit from the presence of national guidelines. Specifically, a review of available data in Jordan was conducted, and statistics compiled regarding the burden of tobacco use, the desire to quit among smokers, and the availability of tobacco dependence treatment HCPs and clinics in the country. Because data were not consistently available, some information was based on the expert opinions of those with several years of experience in the field of tobacco control.

Stage 3 (July-November 2013): Outline and content development. This stage was the most complicated, and involved developing a framework and content for the guidelines and agreeing this among members of the Jordan Tobacco Dependence Treatment Guidelines Group. A review of the most up-to-date information available on tobacco dependence treatment was performed, focusing largely on internationally available guidelines, relevant published literature such as Cochrane and WHO reviews, and successful tobacco dependence treatment models used in other countries. The group also took into consideration the national resources available, the target audience for the guidelines, what actions were expected to be accomplished and the challenges envisioned. Topics to be included in the national guidelines were selected and the content was developed and customized for each topic.

Stage 4 (December 2013): National review. Following a rigorous review by the Jordan Tobacco Dependence Treatment Guidelines Group, the content of the guidelines was then reviewed by a larger group of invited national stakeholders (HCPs representing major health service providers); and finally by a group of international, regional and national tobacco control experts attending a tobacco dependence treatment workshop in Amman, where the guidelines were presented and discussed (21). After each review, the draft guidelines were modified according to the feedback received.

Stage 5 (April 2014): Endorsement and launch. After translating the guidelines into Arabic they were approved and official endorsed by the Jordanian $\mathrm{MoH}$. The guidelines were launched via tobacco dependence treatment training workshops for HCPs from the different health providers in Jordan (Jordanian MoH, Royal Medical Services, United Nations Relief and Works Agency for Palestine Refugees in the Near East, university hospitals and the private sector). The guidelines were then uploaded and disseminated electronically on the treatobacco.net website in both Arabic and English (20). Treatobacco.net is an independent body that collates up-to-date evidencebased information (reviewed by roughly 50 international experts) and posts international guidelines about the treatment of tobacco dependence.

\section{Results}

\section{Situation analysis}

\section{The tobacco epidemic}

The national situation analysis revealed a substantial burden of tobacco use among adults, youth and HCPs in Jordan. The prevalence of regular tobacco use (i.e. cigarettes) among adults was estimated at 32\% (55\% among males and 8\% among females) (7), an increase from the $29 \%$ prevalence in 2007 (6). Prevalence rates were particularly high in certain demographic groups: for example, among men approximately $63 \%$ of 25-44-year-olds were regular tobacco users (7). Among women, average rates of waterpipe use among 15-49-yearolds had risen from $5.5 \%$ in 2009 to $10.3 \%$ in 2012 (22,23). Approximately $61 \%$ of all Jordanian households had at least one smoker (24). The data also indicated that particularly among HCPs (physicians and nurses), smoking rates were higher than the national average (39.0\% overall; $46.9 \%$ among physicians and $36.1 \%$ among nurses) (25). Among youth, the Global Youth Tobacco Survey for 2009 reported rates of $11.5 \%$ and $20.7 \%$ for current cigarette and waterpipe smokers, respectively (26). Finally, among young girls (aged 15-19 years), rates of cigarette and waterpipe use had risen from just under $1 \%$ and $5 \%$ respectively in 2009 to around $8 \%$ and $14 \%$ respectively in $2012(22,23)$.

\section{Need for and availability of tobacco dependence treatment services}

Across a country of around 6 million people, the most current published national estimates indicated that only $2.9 \%$ of adult smokers had successfully quit smoking (27). Adult current smokers represented $32.3 \%$ of the population (7), around $20 \%$ of whom had received professional advice to quit. A high proportion of current smokers, roughly $63 \%$, had tried to quit and failed. Half of current smokers had not heard of smoking cessation services (clinics 
or hotlines), but roughly 53\% said they would likely contact a clinic or hotline (27). More than half (51.3\%) of adolescent current smokers (aged 13-15 years) had the desire to quit, and $63.6 \%$ had tried to quit in the previous year (26).

The national situation analysis also revealed a wide gap between the relatively high level of interest in quitting and the limited access or referral to available treatment. It was clear that the tobacco dependence treatment services available in Jordan were insufficient: only 4 cessation clinics in the country provided tobacco dependence treatment (counselling and pharmacotherapy). One of these, at KHCC (Amman), primarily served cancer patients, so there were only 3 free-of-charge $\mathrm{MoH}$ clinics serving the general public, one in each geographical region of Jordan: Central (Amman), North and South. Telephone support lines (quitlines) had not yet been established. Very recently, selected pharmacies had begun offering tobacco dependence treatment to smokers (28).

There was also evidence that HCPs in the Jordanian $\mathrm{MoH}$ primary healthcare clinics lacked knowledge about the existence of tobacco dependence treatment clinics and did not routinely practise screening for tobacco use. Thus, referral from the Jordanian MoH's primary care clinics to its 3 tobacco dependence treatment clinics was limited. Furthermore, on a policy level, although tobacco dependence treatment was mentioned in the country's National Tobacco Control Plan, there was no clear strategy or programme for it. Rather, tobacco dependence treatment remained a low-grade health priority and did not receive sufficient awareness, promotion, training or funding to sustain it.

\section{Tobacco dependence treatment medications}

The situation analysis noted that first-line medications registered and available in the country included nicotine replacement therapy in the form of patches, gums and lozenges, and varenicline (a nicotinic receptor partial agonist). The antidepressant drug bupropion was not registered at the Jordan Food and Drug Administration but was available at KHCC through a special licence. Unfortunately, it was noted that it was often challenging to sustain the availability of tobacco dependence treatment medication, an issue that further hindered the provision of comprehensive treatment. For example, even with the limited number of patient referrals, $\mathrm{MoH}$ tobacco dependence treatment clinics faced budgetary constraints and drug shortages. Drug shortages were also occasionally being faced at KHCC due to deficiencies in drug supplies.

\section{Trained specialists}

Tobacco treatment specialists, another pivotal element in tobacco dependence treatment, were available in Jordan, although this was largely the result of recent efforts in raising awareness about the tobacco epidemic and treatment. In Jordan, in the previous 2 years, about 200 HCPs (physicians, dentists, pharmacists, nurses) had been trained on advanced tobacco dependence treatment principles, and an additional 327 health educators (school counsellors and teachers) trained in the basic principles of tobacco control and tobacco dependence treatment. While this was seen a positive step, it was recognized that there was a limit to what these numbers of professionals could achieve on a national scale.

\section{Content of the guidelines}

\section{Forms of treatment}

The guidelines included the 2 most widely recognized forms of counselling and treatment for tobacco users: brief intervention the AAR [Ask, Advise, Refer] and 5As [Ask, Advise, Assess, Assist and Arrange] models; and faceto-face support. Any HCP (nurses, physicians, dentists, pharmacists, midwives) can conduct the brief intervention, while the face-to-face support is more likely to be performed by experienced professionals.

The AAR model was included to address HCPs and educators with insufficient expertise or time to conduct intensive counselling. This is the situation in most of the public primary care clinics, where HCPs have often not heard of tobacco dependence treatment and where the high workload does not allow much time for long interventions with patients. The 5As model, was included as an option to be used by HCPs with more expertise and time to speak to patients, but insufficient time to provide face-to face-support.

Face-to-face support requires more interaction with the smoker through intensive and repeated counselling sessions, possibly accompanied by medication use, rather than referral. In Jordan, only physicians are authorized to prescribe medications, and therefore face-to-face counselling involving pharmacotherapies is anticipated to be performed only by physicians. In the Jordan guidelines face-to-face support was focused on individual-based interventions due to the limited local experience with group therapy.

\section{Pharmacotherapy}

Given the importance of pharmacotherapy in tobacco dependence treatment, a separate section of the guidelines was included to address this topic. Only pharmacotherapies currently available in Jordan were covered, while other possible tobacco dependence treatment options, such as cytisine (a partial nicotinic receptor agonist) and clonidine (an alpha-2 adrenergic agonist), were described in brief.

\section{Support to special groups of tobacco users}

Other topics addressed in the guidelines were tobacco use in children and 
adolescents, and waterpipe use: two equally concerning public health issues in Jordan.

\section{Tobacco use in children and adolescents}

The content of this section of the guidelines was developed with both HCPs and school counsellors in mind, given that counselling alone is the recommended line of therapy for tobacco dependence (17).

\section{Waterpipe use}

Use of waterpipes has been increasing in Jordan, but there is currently insufficient evidence to guide the treatment of this form of tobacco use (29). Based on the local experience with treating waterpipe tobacco users, some advice was included in the guidelines on support for waterpipe users who are trying to quit.

\section{Appendices}

A series of appendices to the guidelines provided additional clinical details for HCPsandeducatorsinterestedinplaying an active role in tobacco dependence treatment. Topics in the appendices included the WHO's MPOWER strategies: the health consequences of tobacco use and benefits of quitting; the nature and assessment of nicotine dependence; assessment of motivation to quit; designing quit plans; tobacco withdrawal symptoms and relapse; using carbon monoxide testing in tobacco dependence treatment; specific instructions on tobacco dependence treatment pharmacotherapy; principles of motivational interviewing; and weight management during smoking cessation. Tobacco dependence treatment interventions of debatable value (self-help material; hypnosis; and electronic cigarettes) were noted briefly.

\section{Discussion}

In this paper we describe the development of Jordan's tobacco dependence treatment guidelines, the first comprehensive Arabic-language tobacco dependence treatment guidelines developed in the region, drafted and reviewed by a team of local and international experts, and endorsed by Jordan's national health authority. The guidelines were developed to fill some of the gaps observed in Jordan's tobacco dependence treatment services by promoting the concept of tobacco dependence as a chronic disease and by providing guidance for HCPs and educators on how to help smokers quit. The guidelines are a natural progression for the Jordanian $\mathrm{MoH}$ in its continuing efforts to integrate standardized tobacco dependence treatment services into the national health-care system. By enabling professionals to treat tobacco dependence by referring to these guidelines, it was hoped that treatment services in both the public and private sectors would expand, thereby encouraging pharmaceutical companies and the Jordan Food and Drug Administration to sustain the availability of cessation medications.

Based on anupdated comprehensive review of medical evidence, the guidelines were also designed to take into account Jordan's available resources, and, where appropriate, the content was customized to apply to the local situation in Jordan (including a section on the management of waterpipe users). Furthermore, actions and recommendations included in the guidelines could be applied by a variety of HCPs (nurses, physicians, dentists, pharmacists or midwives) and educators (schoolteachers or counsellors). Finally, the guidelines provided information for health care decision-makers and administrators with regard to the necessary tools and resources for treatment and could also serve as a reference for HCPs and educators in the region.

The process we used to develop our guidelines was consistent with internationally available standards for guideline development and appraisal (30). The guidelines, however, are a work in progress, requiring substantial follow-up as well as ongoing efforts. For example, it is imperative that the content of our guidelines reflects up-todate medical evidence and is adapted to the changing local environment (e.g. the availability of additional pharmacotherapies or the inclusion of additional high-risk groups such as pregnant women). The updating of tobacco dependence treatment guidelines varies from country to country (20), and no standards for how often to update guidelines have been recommended. It will therefore be left to the judgement of the involved group of experts who developed Jordan's tobacco dependence treatment guidelines to decide on this.

Furthermore, a clear dissemination and monitoring mechanism is required for the guidelines. With regard to dissemination, a local tobacco dependence treatment training workshop was held to coincide with the official endorsement and launching of the guidelines. The workshop aimed to train attendees (HCPs and educators from public and private health-care organizations) in tobacco dependence treatment, while specifically linking the topics in the training course to the contents of the recently launched guidelines. This was valuable for highlighting how the content of the Jordanian guidelines could be used by the participants during their daily practice. Hard and soft copies of the guidelines were distributed to attendees, and are readily available upon request. The national guidelines were also posted on the KHCC's clinical practice guidelines website and were uploaded onto the treatobacco.net website (20). Given that educational outreach and interactive educational workshops are effective mechanisms to promote clinical practice guidelines (31), Jordan's tobacco dependence treatment guidelines are currently 
presented and disseminated in all tobacco dependence treatment and tobacco control conferences and workshops conducted nationally, regionally or internationally by KHCC and the Jordanian $\mathrm{MoH}$.

A monitoring and evaluation mechanismforourguidelinesiscurrently being planned. Ideally, monitoring of the guidelines will require the design of a rigorous system to assess any emerging barriers to implementation and the extent of implementation of the guidelines and adherence to the recommendations. Also needed are a set of clear process and outcome measures that can be tracked to ensure the guidelines are being implemented and to bring about change in the process of care and patient outcomes, and to highlight where further work and research will be needed (31). In the case of Jordan's tobacco dependence treatment guidelines, a feasible monitoring plan will be designed which takes into account the availability of resources as well as the desired scope of guideline implementation (particularly if local decision-makers deem it more practical for guideline implementation to be gradually rolled out across clinics in selected health care sectors).

Adoption of these guidelines in Jordan and, ideally, elsewhere in the region, has the potential to make a substantial contribution to publichealth. As the first comprehensive guideline published in Arabic, and as a means of complying with the requirements of nations who have ratified the WHO FCTC (i.e. most nations in the Arabicspeaking world), these guidelines may be effective in reducing the death, disease and economic disruption caused by all forms of tobacco smoking.

\section{Acknowledgements}

We would like to acknowledge the efforts of Dr Martin Raw (UK Centre forTobacco Control Studies, University of Nottingham) for his technical advice during the guideline development process and for providing comments during manuscript generation.

Funding: KHCC is a grantee of the Mayo Clinic (USA) for conducting Global Bridges work in the Eastern Mediterranean Region. Development of the guidelines was funded in part by this grant.

Competing interests: None declared.

\section{References}

1. WHO report on the global tobacco epidemic, 2011. Warning about the dangers of tobacco. Geneva: World Health Organization; 2011 (http://www.who.int/tobacco/global_report/2011/en/, accessed 20 September 2015).

2. The health consequences of smoking-50 years of progress: a report of the Surgeon General. Atlanta (GA): Centers for Disease Control and Prevention; 2014 (http://www.surgeongeneral.gov/library/reports/50-years-of-progress/, accessed 20 September 2015).

3. Beaglehole R, Bonita R, Horton R, Adams C, Alleyne G, Asaria $P$, et al.; Lancet NCD Action Group; NCD Alliance. Priority actions for the non-communicable disease crisis. Lancet. 2011 Apr 23;377(9775):1438-47. PMID:21474174

4. Mokdad AH, Jaber S, Aziz MI, AlBuhairan F, AlGhaithi A, AlHamad NM, et al. The state of health in the Arab world, 1990-2010: an analysis of the burden of diseases, injuries, and risk factors. Lancet. 2014 Jan 25;383(9914):309-20. PMID:24452042

5. Rahim HF, Sibai A, Khader Y, Hwalla N, Fadhil I, Alsiyabi H, et al. Non-communicable diseases in the Arab world. Lancet. 2014 Jan 25;383(9914):356-67. PMID:24452044

6. Al-Nsour M, Zindah M, Belbeisi A, Hadaddin R, Brown DW, Walke $H$. Prevalence of selected chronic, noncommunicable disease risk factors in Jordan: results of the 2007 Jordan Behavioral Risk Factor Surveillance Survey. Prev Chronic Dis. 2012;9:E25. PMID:22172192

7. Jaghbir M, Shreif S, Ahram M. Pattern of cigarette and waterpipe smoking in the adult population of Jordan. East Mediterr Health J. 2014 Sep;20(9):529-37. PMID:25343465

8. Mortality in Jordan 2009 [Internet]. Amman: Ministry of Health Jordan; 2009 (http://moh.gov.jo/MOH/Files/Publication/ al\%20seha\%20net_1.pdf, accessed 19 January 2015).

9. Prevalence of chronic disease in Jordan 2010 [in Arabic]. Amman: Department of Statistics; 2010 (http://www.hpcpromise.
org.jo/sites/default/files/researches/articles/Amrad\%20 mozmena-2010.pdf, accessed 20 September 2015).

10. Jordan cancer registry. Annual incidence of cancer in Jordan 2010. Amman: Ministry of Health; 2010 (http://moh.gov. jo/Documents/Annual\%20Incidence\%20of\%20cancer\%20 in\%20Jordan\%202010.pdf, accessed 19 January 2015).

11. Hawari Fl, Bader RK. Advancing tobacco dependence treatment services in the Eastern Mediterranean Region: international collaboration for training and capacity-building. Sultan Qaboos Univ Med J. 2014 Nov;14(4):e442-7. PMID:25364544

12. WHO Framework Convention on Tobacco Control. Geneva: World Health Organization; 2003 (http://www.who.int/fctc/ text_download/en/, accessed 20 September 2015).

13. West R, Raw M, McNeill A, Stead L, Aveyard P, Bitton J, et al. Health-care interventions to promote and assist tobacco cessation: a review of efficacy, effectiveness and affordability for use in national guideline development. Addiction. 2015 Sep;110(9):1388-403. PMID:26031929

14. Framework Convention on Tobacco Control. Guidelines for implementation of Article 14. Guidelines on demand reduction measures concerning tobacco dependence and cessation. Geneva: World Health Organization; 2010 (http://www. who.int/fctc/guidelines/adopted/article_14/en/, accessed 20 September 2015).

15. European smoking cessation guidelines: The authoritative guide to a comprehensive understanding of the implications and implementation of treatments and strategies to treat tobacco dependence. 1st ed. Brussels: European Network for Smoking and Tobacco Prevention; 2012 (http://www.ensp. org/sites/default/files/ENSP-ESCG_FINAL.pdf, accessed 20 September 2015).

16. Supporting smoking cessation: a guide for health professionals. Melbourne: The Royal Australian College of General Practitioners; 2011 (www.racgp.org.au/guidelines/smokingcessation, accessed 20 September 2015). 
17. Fiore MC, Jaén CR, Baker TB, Bailey WC, Benowitz NL, Curry SJ, ET al. Treating tobacco use and dependence: 2008 update. Clinical practice guideline. Rockville (MD): US Department of Health and Human Services; 2008 (http://www.ahrq.gov/ professionals/clinicians-providers/guidelines-recommendations/tobacco/clinicians/update/index.html, accessed 20 September 2015).

18. Smoking cessation clinical practice guideline. Toronto: Canadian Action Network for the Advancement Dissemination and Adoption of Practice-informed Tobacco Treatment; 2011 (https://www.nicotinedependenceclinic.com/English/ CANADAPTT/Guideline/Introduction.aspx, accessed $20 \mathrm{Sep}-$ tember 2015).

19. Harrison MB, Legare F, Graham ID, Fervers B. Adapting clinical practice guidelines to local context and assessing barriers to their use. CMAJ. 2010 Feb 9;182(2):E78-84. PMID:19969563

20. National cessation guidelines [Internet]. Treatobacco.net. (http://treatobacco.bwa-subway4.co.uk/site/en/page_549. php, accessed 20 September 2015)

21. Jordan hosts a regional conference on strengthening tobacco dependence treatment [Internet]. Rochester (MN): Global Bridges; 2013 (http://www.globalbridges.org/News/Blog/ Jordan-hosts-a-regional-conference-on-strengthening-tobacco-dependence-treatment, accessed 18 September 2015).

22. Jordan Population and Family Health Survey 2009. Amman Department of Statistics/ICF Macro; 2009 (www.dos.gov.jo/ sdb_pop/sdb_pop_e/pop_2009.pdf, accessed 20 September 2015).

23. Population and family health survey, Jordan 2012. Amman: Department of Statistics/ICF Macro; 2012 (http://microdata worldbank.org/index.php/catalog/1908, accessed 20 September 2015).
24. Smoking in Jordan, 2010 [in Arabic]. Amman: Department of Statistics; 2011 (www.dos.gov.jo/sdb_pop/sdb_pop_a/Smoking_2010.pdf, accessed 20 September 2015).

25. Shishani K, Nawafleh H, Jarrah S, Froelicher ES. Smoking patterns among Jordanian health professionals: a study about the impediments to tobacco control in Jordan. Eur J Cardiovasc Nurs. 2011 Dec;10(4):221-7. PMID:20826114

26. Tobacco Free Initiative: Global Youth Tobacco Survey fact sheets and country reports-Jordan, 2009 [Internet]. Geneva: World Health Organization; 2009 (http://www.emro.who.int/tobacco/gtss-youth-survey/gyts-factsheets-reports.html, accessed 20 September 2015).

27. Jaghbir M, Shareif S, Ahram M. Quitting smoking and utilization of smoking cessation services in Jordan: a population-based survey. East Mediterr Health J. 2014 Sep;20(9):538-46. PMID:25343466

28. Quit smoking [Internet]. Pharmacy 1 (http://www2.pharmacy-1. com/CustomerCenter/SmokingForm.aspx, accessed 20 September 2015)

29. Maziak W, Jawad M, Jawad S, Ward KD, Eissenberg T, Asfar T. Interventions for waterpipe smoking cessation. Cochrane Database Syst Rev. 2015;7:CD005549. PMID:26228266

30. Brouwers MC, Kho ME, Browman GP, Burgers JS, Cluzeau F, Feder G, et al.; AGREE Next Steps Consortium. AGREE II: advancing guideline development, reporting and evaluation in health care. CMAJ. 2010 Dec 14;182(18):E839-42. PMID:20603348

31. SIGN 50. A guideline developer's handbook. Edinburgh: Scottish Intercollegiate Guidelines Network; 2014 (http://www.sign. ac.uk/pdf/sign50.pdf, accessed 20 September 2015). 